\title{
KAL'AS'A DUR Museum and Cultural Centre: The Rebirth of a Dying People and Culture
}

\author{
Shabnam Bahar Malik ${ }^{1}$ \\ ${ }^{1}$ R\&D/ORIC, Bahria University, Islamabad, Pakistan \\ Correspondence: Shabnam Bahar Malik, Bahria University, Shangrilla Road, Sector E-8, Islamabad, Pakistan. \\ Tel: 92-51-926-3419. E-mail: drd@bahria.edu.pk
}

Received: September 24, 2012

doi:10.5539/ass.v9n2p278
Accepted: November 5, 2012 Online Published: January 28, 2013

URL: http://dx.doi.org/10.5539/ass.v9n2p278

\begin{abstract}
The newly established KAL'AS'A DUR (the House of Kalasha) the Kalasha Museum and Cultural Centre (2002-2004) in Brua Village in Bumburet Valley of District Chitral in Khyber-Pakhtunkhwa Province (KPK) of Pakistan, is a new tourist attraction that entails a lot of cultural and heritage value. This first and only Kalasha Museum and Cultural Centre has given a new birth to the fast disappearing Kalasha people and their ancient culture. At the same time the Museum is under constant threat from armed conflict and terrorism in the region.

The Kalasha Cultural Centre has six departments but this article will only focus on one department that is Ethnological Museum [or Kalasha Museum] and the heritage collections housed in it. Built by the NGO, Greek Volunteers, the museum houses a great collection of material cultural artifacts of endangered Kalsha Kafirs, an ethnic minority of Pakistan almost at the verge of extinction. Only 3,000 left in three Kalasha Valleys. This article contributes to the Kalasha material culture studies literature by documenting the heritage collections showcased in the Kalasha Museum. Further, it highlights the opportunities of empowerment the museum has provided to the fast declining numbers of Kalasha people and to reviving and preserving their unique cultural heritage. The article also intends to promote the establishment of this first ever Kalasha Museum and the newly opened up opportunities for scholars, researchers, conservation scientists, museums personnel, heritage tourists, and international organizations like ICOM, who can be instrumental in promoting the cause of the endangered Kalasha people and their ancient traditions, through further research and documentation.
\end{abstract}

Keywords: Kalasha Museum, material culture, Kalasha people, endangered, preservation

\section{Introduction}

Realizing the importance of heritage, on 16 November 1972 the General Conference of the UNESCO adopted the "Convention Concerning the Protection of World Cultural and Natural Heritage." The Convention has completed its forty years (1972-2012) and is considered the most successful of all the UNESCO conventions, UNESCO (2012: 2). Similarly in 1946 ICOM (International Council of Museums) was created that established International Museum Day in 1977, celebrated on 18 May around the globe "to encourage public awareness of the role of museums in the development of society." The theme of the 2012 International Museum Day is "Museums in a Changing World."

To promote and preserve the endangered Kalasha people and culture, KAL'AS'A DUR, (as it is called in Kalasha-mun, the Kalasha language) the Kalasha Museum and Cultural Centre was established during 2002-2004 by the NGO "Greek Volunteers." Unfortunately the chairperson of the NGO [Athanassios Lerounis] was abducted from KA'LAS'A DUR in September 2009 by Taliban, and released after eight months in captivity, Rana (2011). After this incident, it was reported by the museum staff, that not only Lerounis never came back but regular summer visits of the Greek doctors also stopped. This has adversely affected the Greek and local efforts to revive and preserve the ancient belief system, language and culture of the only surviving Kalasha People of Pakistan.

It is built on an area of 2000 square meters (Activities and Projects by the NGO "Greek Volunteers" n.d.). This project was financed by the Hellenic Aid of the Greek Ministry of Foreign Affairs and was constructed by two cooperative NGOs, "The Greek Volunteers" and the "Kalasha People Welfare Society." The Museum (The "Ethnological Collection Centre of the Kalasha Culture and the wider Hindu-Kush area," is under the 
supervision of the Archaeology and Museums Department of Khyber-Pakhtunkhwa Province). The Institution of KAL'ASA'A DUR is managed by the Kalasha members of its Managing Committee.

The museum generates some income from ticket sales. Entry ticket for locals is Rs 10, the ticket for using camera in the museum is Rs 200, and Rs 300 to visit the Research Centre and other areas. The Museum Shop also sells replicas and reproductions of the selected local crafts (see Figure 21).

The three-story Kalasha Dur has following six departments:

1) Outpatient Clinic for women and children

2) School of the Kalasha Tradition

3) Seminar halls for traditional and other technical training

4) Library

5) Ethnological Museum [Kalasha Museum]

6) Research Centre

\section{Historical Background}

Made famous in 1896 by G.S. Robertson's study "The Kafirs of the Hindu Kush,” Klimburg (2005: 502-7) the Kalasha Kafirs of Pakistan, a Macedonian people who trace their ancestry with Alexander the Great are an ethnic minority who speak a Dardic Language and adhere to an ancient polytheistic-animistic belief system and hence termed as "Kafirs" or non-believers. They are currently living in three valleys of Rumbur, Bumburet, and Birir in Chitral District, in Khyber-Pakhtunkhwa (KPK) Province of Pakistan. Only 3,000 left, according to the estimates of Maggi and A.S. Cacopardo, Klimburg (2008: 195-209). A more recent news article talked about a workshop on "importance of the preservation of increasingly extinct cultures," held in Folk Heritage Museum Islamabad on dossier preparation for inscription of the Kalasha Valley [s] culture on the World Heritage List, and also reconfirmed this number, stating "The Kalash population fell from 10, 000 in 1951 to 3,700 in 2011, Express Tribune (2012: 14).

Following the pioneering work of Robertson on the social life of Kalasha people numerous studies have been undertaken on various aspects of Kalasha People and their exotic primitive cultural practices; including Germans, Italians, British, Americans, Canadians, French, Austrians and Pakistani scholars. Some of the important studies include, Graziosi (1961-64), A.M. and Cacopardo (1985, 2011), Jettmar (1959, 1986, 1996, 2008), Darling (1979), Loude (1988), Maggie (1995), Snoy (2008: 36-64), Parkes (1983), Klimburg (1999,2005,2008), Buddruss (2008: 16-35), Frembgen (2008: 253-9), Lines (1988, 2008, 2010), Wutt (1978, 1981) and Dani (2001: 420-9). In addition, a rich scholarly collection of articles on Kalasha people is also found in the proceedings of the three International Hindu-Kush Cultural Conferences, published in the1970, 1996, and 2008. Numerous anthropological studies on various aspects of Kalasha culture have also been added to the existing list more recently.

With greater accessibility by first jeep road in 1960, Lines (2008) scores of inquisitive tourists, hunters, merchants, journalists and researchers including anthropologists started visiting the three remote and isolated Kalasha Valleys to see, exploit and study the only surviving Kalasha Kafirs and their exotic ancient culture. Their fast declining numbers estimated to be 3,000 only at present according to the estimates of Maggi et al. (2008) is a point of great concern for the scholars and conservationists to address the urgent need to preserve their fast disappearing cultural heritage.

The Kalasha People are at present under mounting threat of extinction in the face of aggressive modernization, tourism and surrounding Islamic proselytization, Klimburg (2008). Albeit, much has been said and written on Kalasha People and their ethnology, but not a single systematic study has been conducted on their "Material Culture" or the study of Kalash material artifacts so far, because not a single such institution was ever established to promote Kalasha people and their culture.

The material cultural objects contain vital information about the culture where they were made, why and how they were made, what materials were used, what technologies were applied, and the circumstances in which they were created - information that can be recorded and preserved for the present and future generations. The care and knowledge associated with artifacts ultimately ensures their existence for generations, CCI Symposium (2007: 7-8).

Due to endangered status of Kalasha People many recent studies emphasize that greater efforts are needed by conservation experts, development workers and anthropologists to preserve Kalasha culture, Abbasi (2011: 26). 
The present study on newly established Kalasha Museum at Bumburet Valley, which is the bigger and more touristic of the three Kalasha Valleys, shall attempt to present the pioneering research on this institution and the material objects displayed in the museum with a motive to raise awareness about this knowledge resources on Kalasha People, and its future value as a repository of Kalasha material culture that can be used for further study, preservation and promotion of the endangered Kalasha people and their ancient traditions.

The recent establishment of the Kalash Museum has opened up a new and unique opportunity for research scholars including anthropologists, who can now gain a greater understanding of the native Kalasha material cultural objects within their museum by being able to visit the community of origin to observe how the objects were traditionally made and used, for instance, in their numerous festivals and ceremonies and daily lives. And how to this day, on all important festivals and occasions Kalasha People use these material objects to reinvent their social identity, kin networks and perform religious obligations.

The present study, intends to bring to the limelight the establishment of the Kalasha Museum, the categories of artifacts displayed in the museum, and propose a more extensive systematic scientific study and analysis of the material cultural artifacts of Kalasha People, using "heritage collections" housed in the Kalasha Museum. I strongly hope that this would help to preserve and revive the endangered and fast disappearing Kalasha people and cultural heritage of Pakistan.

\section{The Kalasha Museum}

The Kalasaha Museum is part of a three-story building that houses all six departments that constitute KAL'AS'A DUR or the House of Kalasha, (see Figures 2 and 3). The Museum exhibits are housed at ground floor. The building is a beautiful specimen of local ancient architectural style using logs and local stone, (see Figure 1). The establishment of the KAL'AS'A DUR was financed by the Hellenic Aid of the Greek Ministry of Foreign Affairs, Museum Brochure (n. d.).

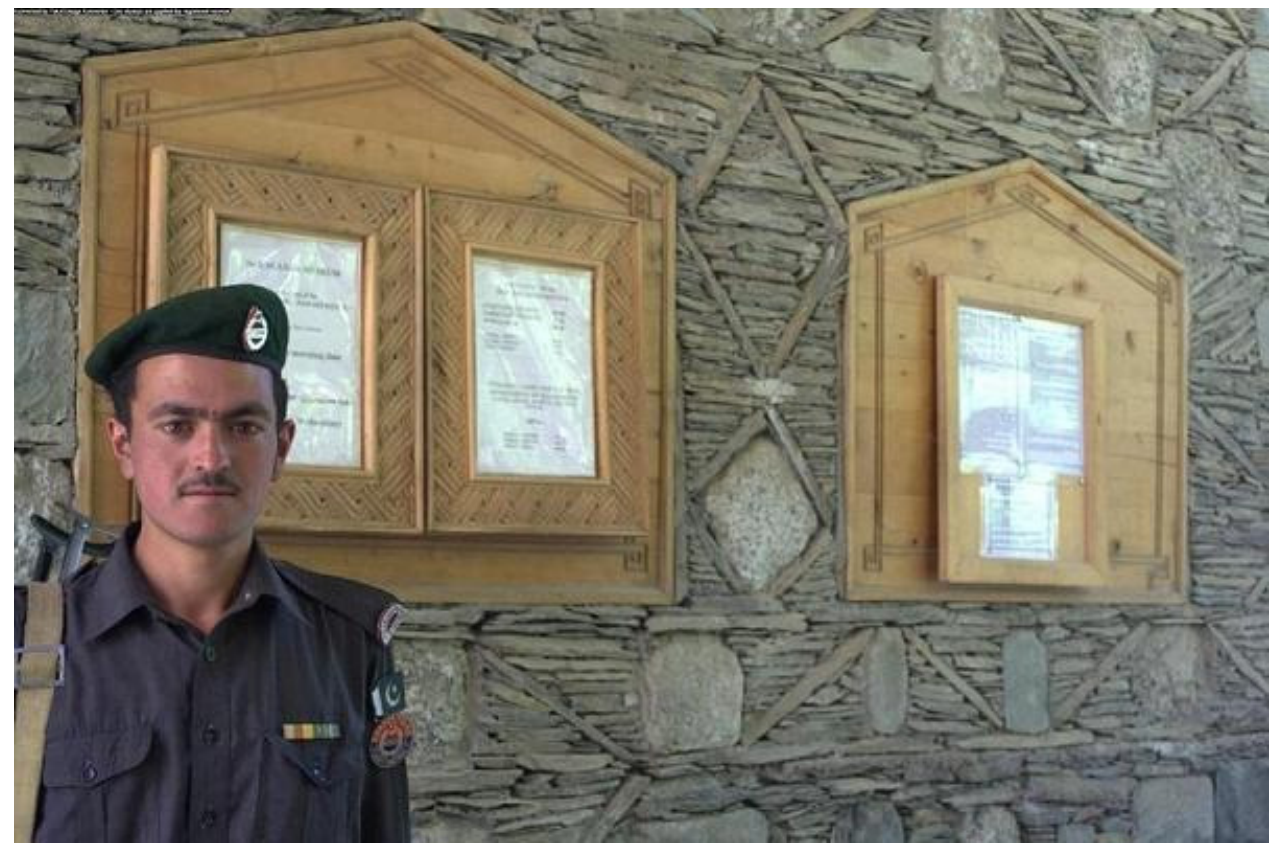

Figure 1. Museum guard at the entrance of the Kalasha Museum

Photograph by Author, 2011 


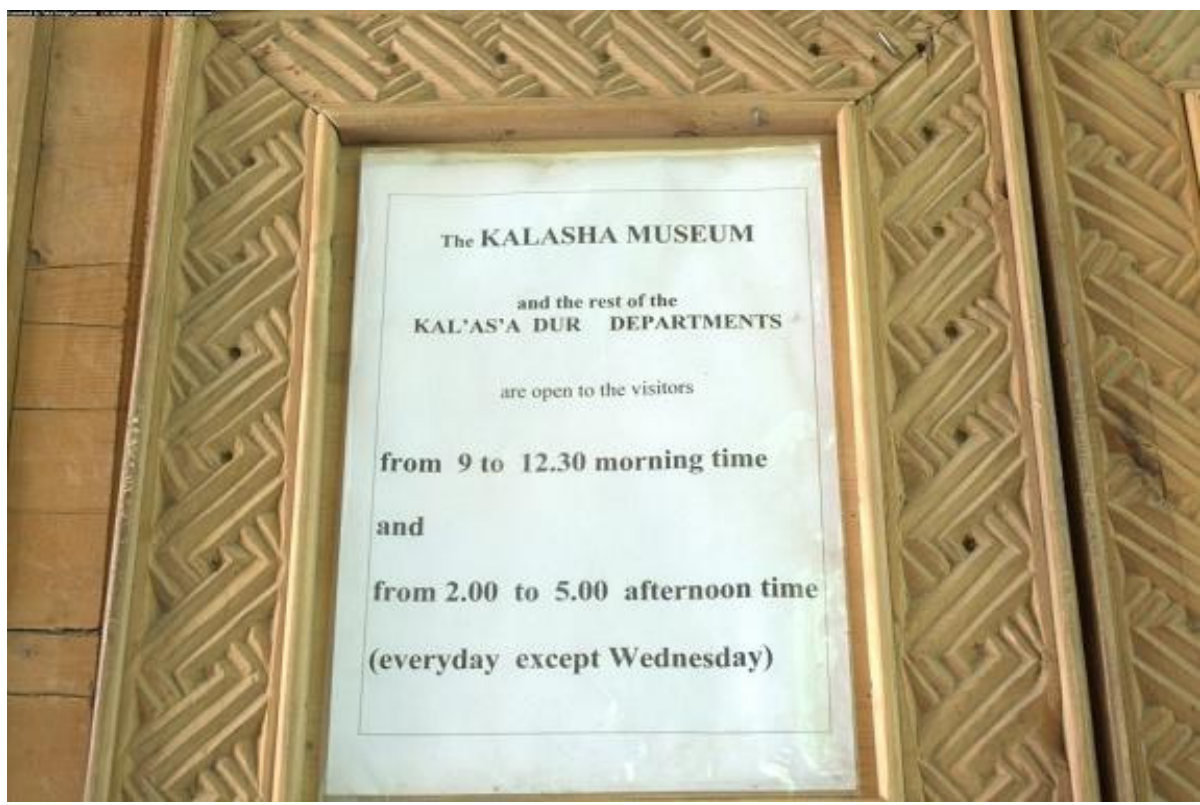

Figure 2. Plaque at the entrance of the Kalasha Museum

Photograph by Author, 2011

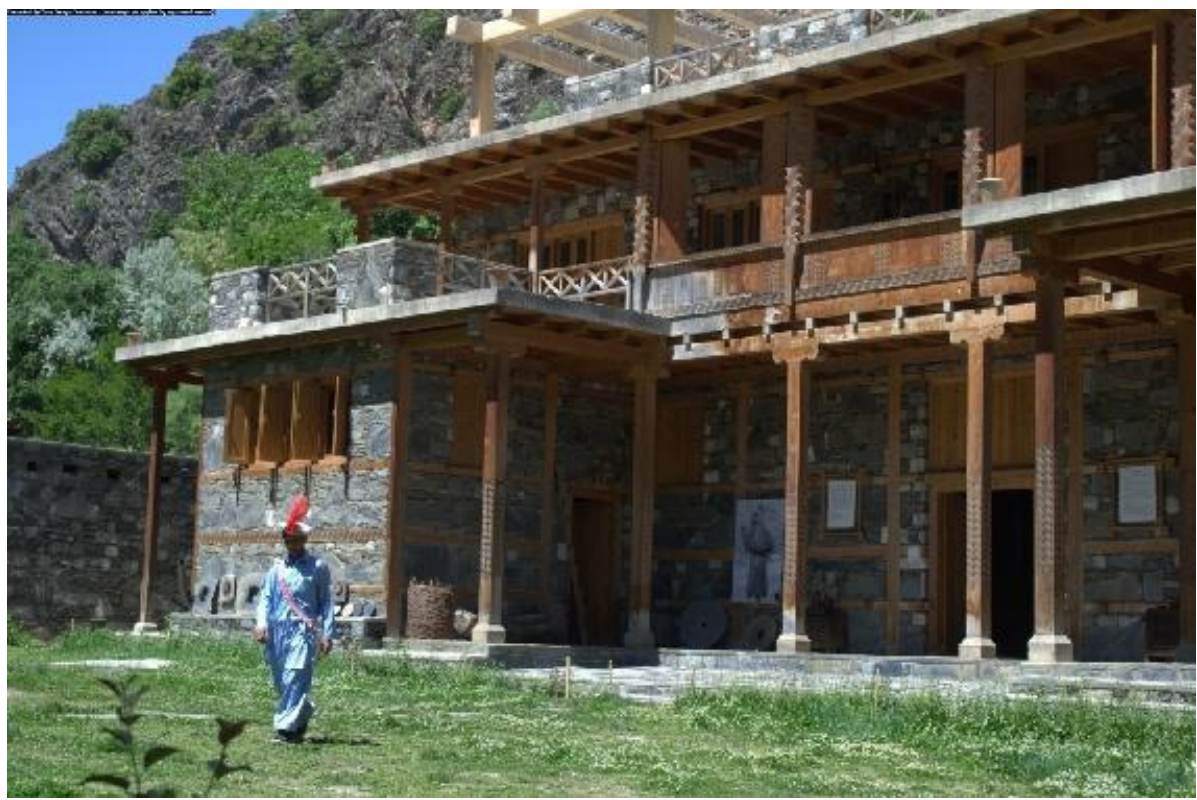

Figure 3. The KAL'AS'A DUR Museum and Cultural Centre

Photograph by Author, 2011

The Kalasha Museum is a newly established museum, keeping in view the endangered culture and people of three-Kalasha Valleys; it was built in 2002-2004. It is a traditional style museum, more or less an object repository of material cultural objects of the Kalasha people. Where all collections are illuminated and housed within wooden glass frames safely locked. As compared with various contemporary more interactive museums built to highlight the native people and cultures, for instance the National Museum of the American Indian in Washington DC, Issac (2008:287).

The setup of the museum shows traditional modes of showcasing and interpreting collections. A knowledgeable English speaking native Kalasha museum guide, who is well versed with Kalasha language, history and ancient cultural traditions, walks visitors through various exhibits and galleries.

There is a need to prevent the museum from overcrowding, as space is narrow and some displays are open and hence open to robbery and theft. 
The objects layout in exhibit cases presents them as ethnographic pieces without any scientific categorization. Most of the tags show local names of objects, written only in Kalasha language, without an accompanying English translation for a visitor/ foreign tourist, who come in great numbers on all major Kalasha festivals.

The knowledge that is transmitted by viewing various museum exhibits comes solely from Kalasha material culture encased and displayed in the museum. The display and study of these artifacts shall empower the endangered Kalasha people and lend them a voice in the long run as more and more visitors and tourists come to see their ancient cultural practices and the knowledge that is transmitted now through the pieces of their unique material cultural heritage, so immaculately showcased in the newly built Kalasha Museum.

The construction of the Museum building and exhibits draw heavily on indigenous features and materials, like wood, stone, carving and style of architecture, to highlight the ancient Kalasha aesthetics of building their spaces and objects. The local carpenters were employed, it was told, to reproduce the ancient motifs of carvings on doors, door handles, pillars and exhibit cases in the Museum.

\section{The Categories of Artifacts in the Museum}

The Kalasha Museum contains a large array of objects, from costumes to jewelry, to household items to local traditional artifacts. The region has a long tradition of using locally available resources like timber and stone in households as well as in the construction style. Keeping with the tradition, the museum also houses carved wooden parts of old Kalasha temples, clay pots, wooden funerary statues or Gandaus, domestic utensils, basketry, old furniture and weaving tools.

In the subsequent sections each category of artifacts shall be discussed in some detail, supported with museum-based visuals depicting the ways item are arranged and displayed in the Museum.

\subsection{Traditional Costumes of Kalasha Men and Women}

Kalasha People are most famous for their unique and colorful dress heritage, depicting their love for life, that include various pieces that together make the most unique dress style in the world for women. The main dress for a woman included, Cheo $[\mathrm{cew}]$ in the past (the traditional black woolen dress) or lately Piran (the new black dress made with cotton or linen cloth with woolen embroidery). The belts called chehari and shuman, the bunches of beaded necklaces, called sulki maik and gadul'ai and the most incredible two ornate headdresses called kupas (Figure 11) and shushut (Figure 7). Shushut is used for day-to-day use whereas kupas is used on all important occasions including all Kalasha festivals.

For men woolen pants sualak [shualak] worn by goatherds, and the traditional ornate leather moccasins called kalun (see Figure 4) were used about 50 years from now, Farman (personal communication, April 2012). A good brand was sara [shara] kandali kalun, the decorative moccasins made from markhor leather (Trail and Cooper 1999:147-287). During death rituals a male dead body is dressed with kalun as well. At present both men and women use sandals and sneakers. No use of kalun was observed during a May 2011 visit to watch the spring festival Chilim Jusht or Joshi. Kalun were told to be used inside as well as outside as they were carefully made using layers of raw leather as a base or sole. The shoes were tied with colorful thin belt-like laces with colorful pompoms at the ends. The color of shoes was natural beige with woolen embroidery around the shoes, on sale in a Kalasha Stall set up during Folk Festival 2012 in Islamabad (priced at Rs 3000/ about US\$ 35). 


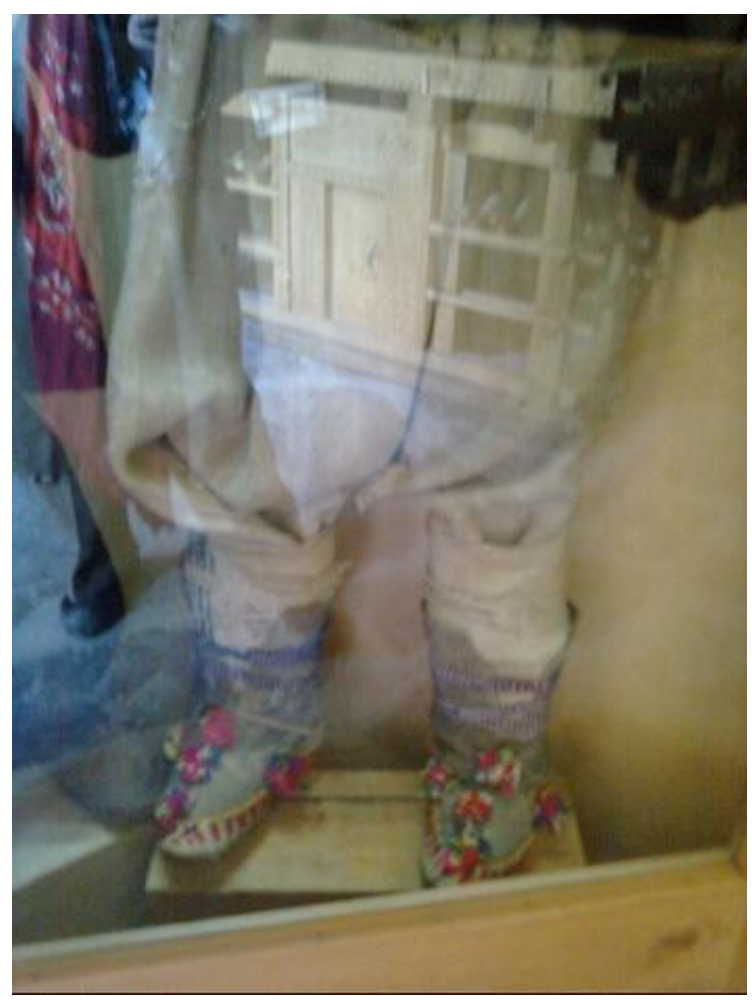

Figure 4. Traditional woolen pants of men 'sualak' [shualak] and leather moccasins 'kalun' Photograph by Author, 2011

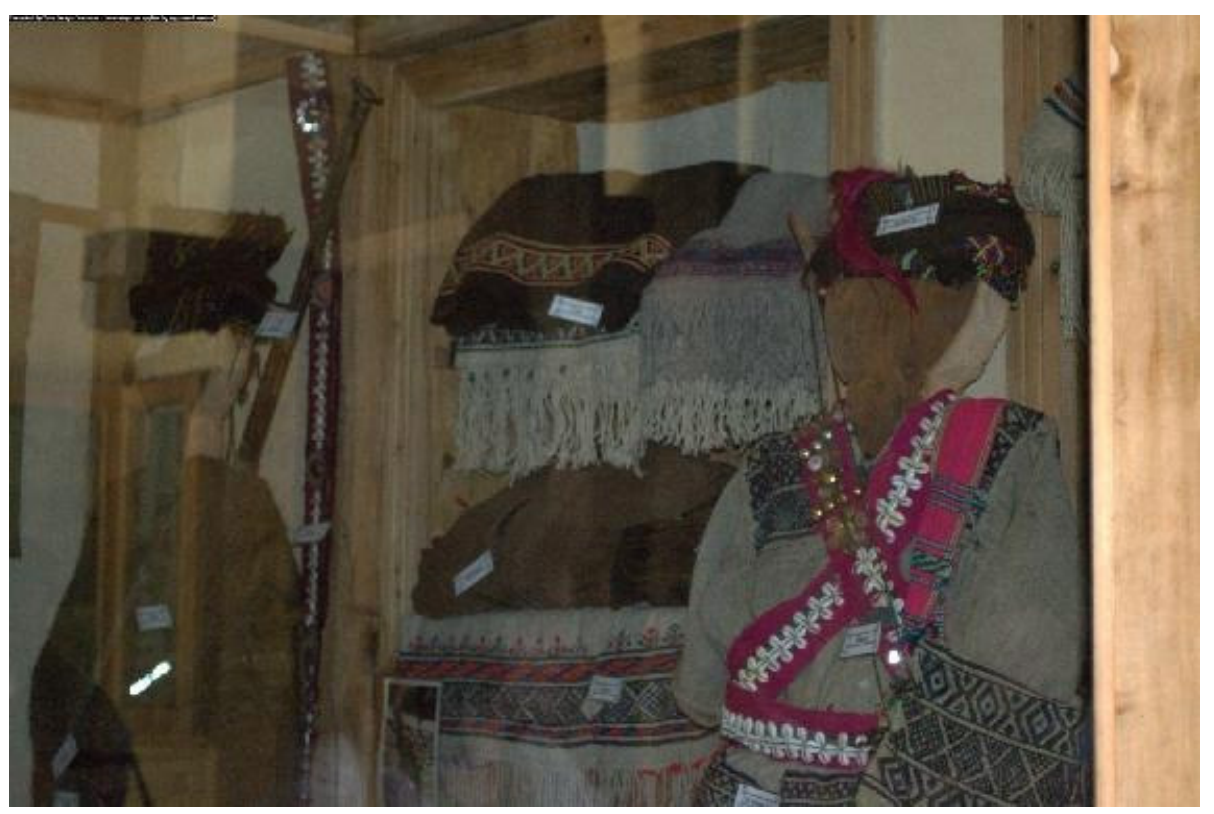

Figure 5. A museum shelf displaying men's traditional dress and accessories

Photograph by Author, 2011 


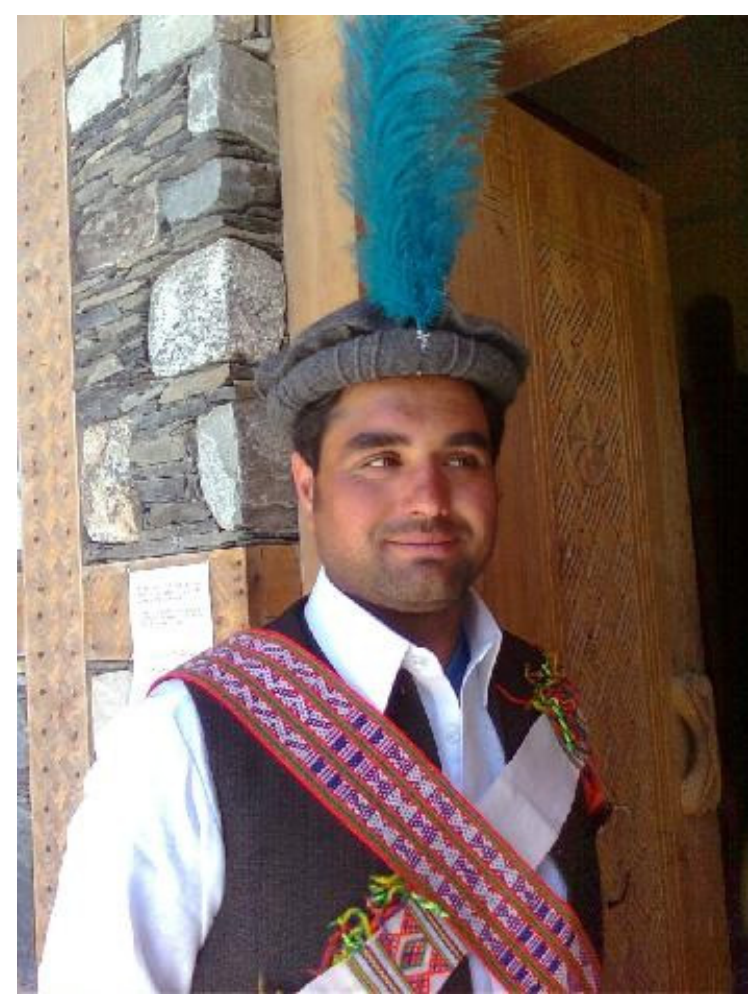

Figure 6. The Kalasha Musuem guide in his traditional men's belts 'suman' and cap Photograph by Author, 2011

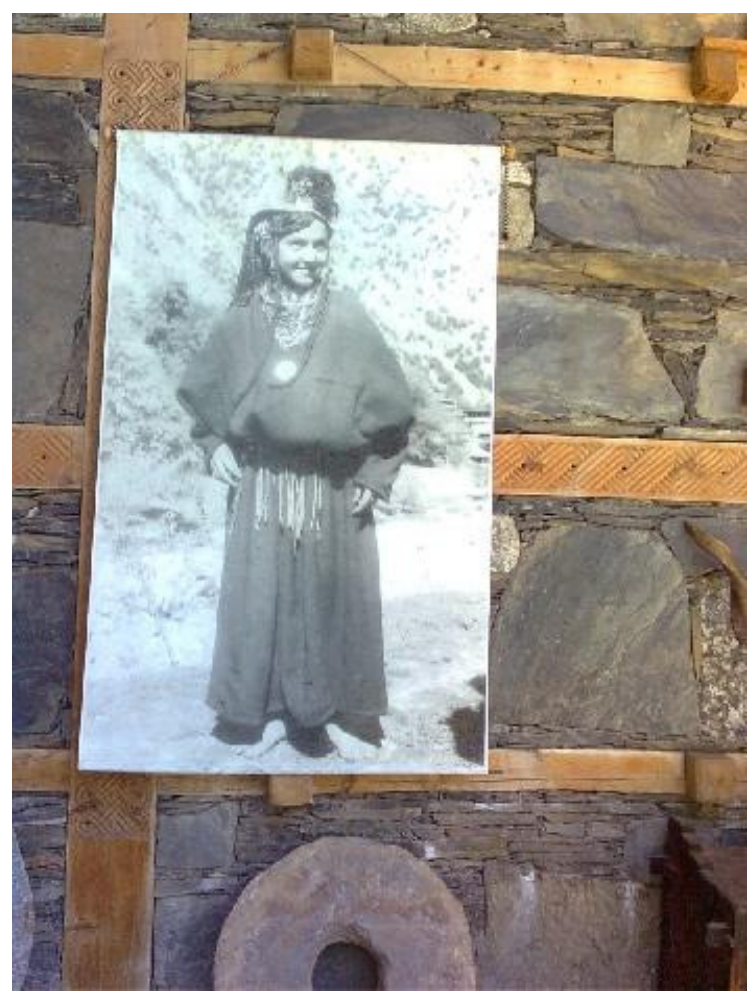

Figure 7. The traditional Kalasha woman's woolen dress 'cew' [Cheo]

Photograph by Author, 2011 


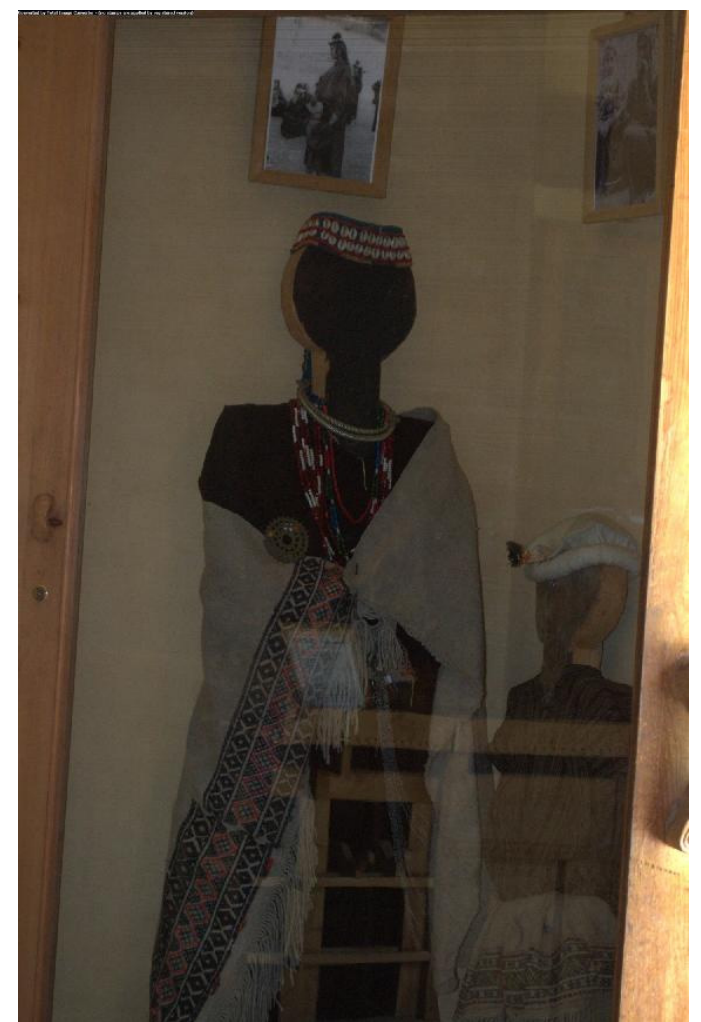

Figure 8. A traditional woman's dress and shawl with accessories

Photograph by Author, 2011

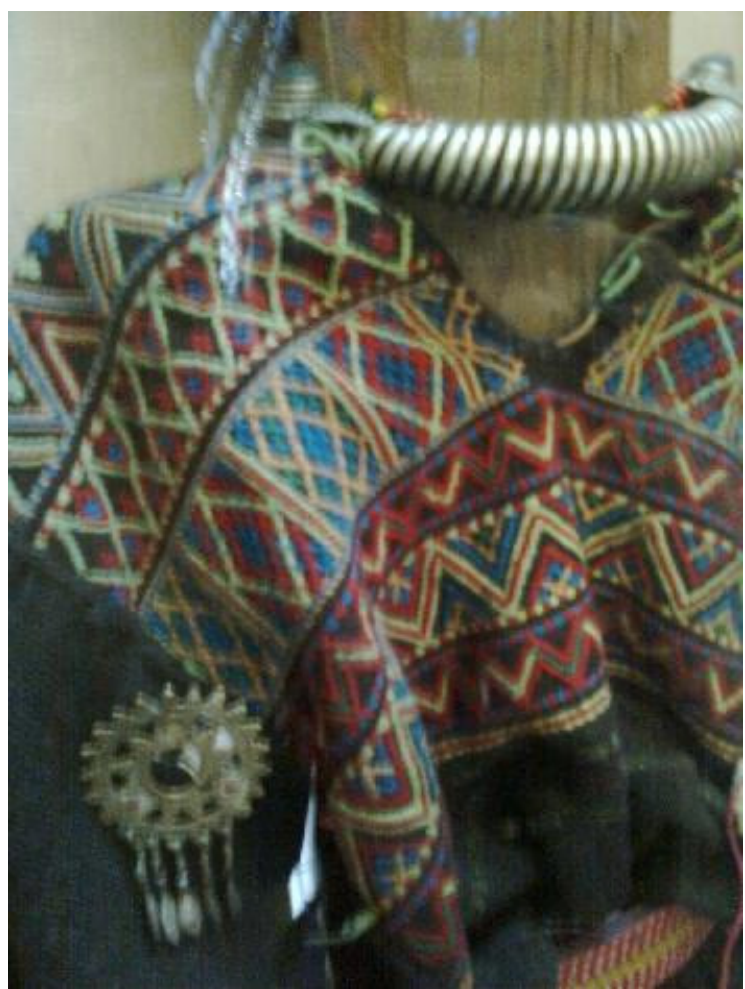

Figure 9. An old embroidered top of a Kalasha woman's dress

Photograph by Author, 2011 


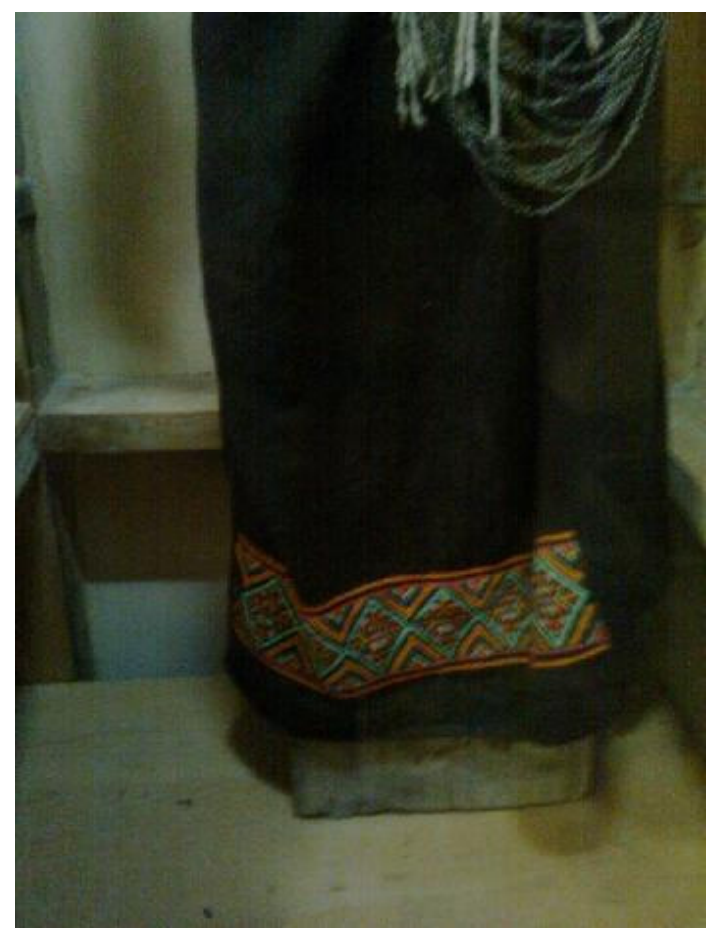

Figure 10. An old embroidered bottom of a Kalasha woman's dress

Photograph by Author, 2011

\subsection{The Ornate Kalasha Headdress 'Kupas'}

The most beautiful and ornate headdress worn by Kalasha women include two exclusive and unique pieces of headdress, called Kupas and Shushut, (see Figures 11 and 12).

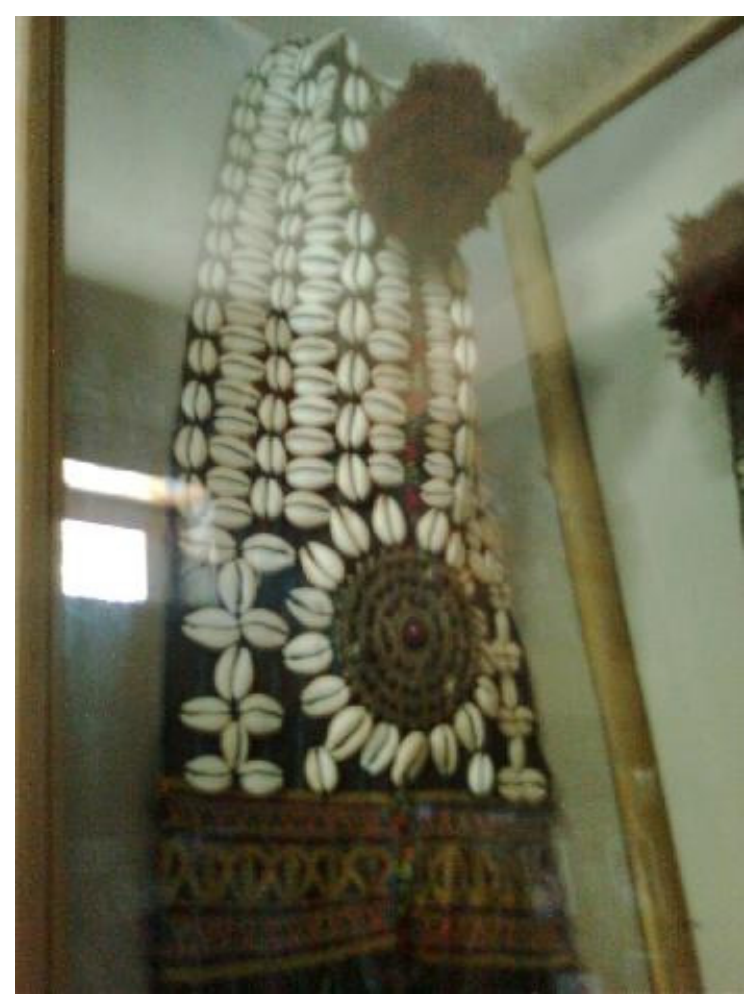

Figure 11. An old specimen of the 'Kupas' headdress of Kalasha women displayed in the museum Photograph by Author, 2011 


\subsection{Shushut}

The minor headdress shushut, a decorated headband with ornate tail hanging at the back, is worn all the time under the main headdress kupas.

4.4 Jewelry

Kalasha women use excessive beaded jewelry as necklaces in their entire life, in a variety of colors and bead styles. The old photographs however show a lesser use of bead necklaces (see Figure 12).

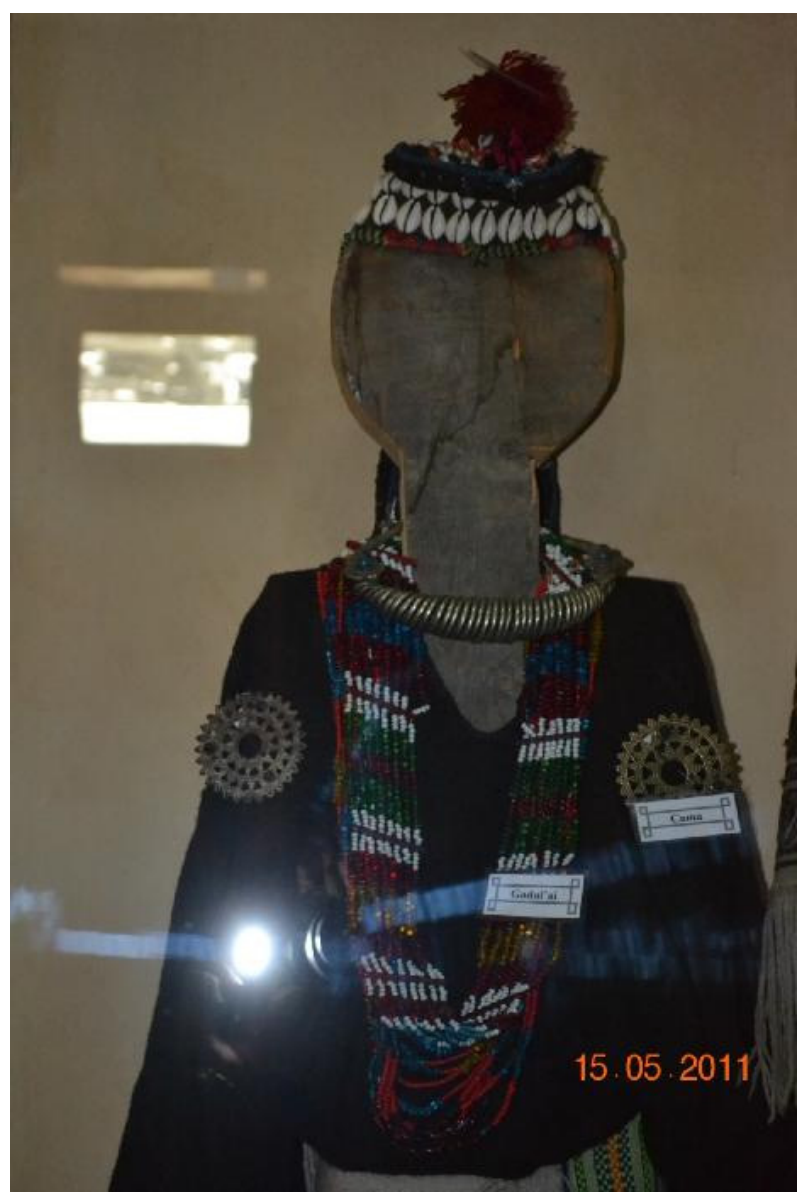

Figure 12. Traditional Kalasha headdress shushut and jewelry

Photograph by Author, 2011

\subsection{Basketry}

The Kalsha live in natural surroundings, and produce a variety of basketry, see Figure 13 . The famous conical Khawa baskets, Sperber (1996: 399), "woven from goat hair around a structure composed of mulberry and wild almond branches," used for carrying loads from farm to home by women, is an example. 


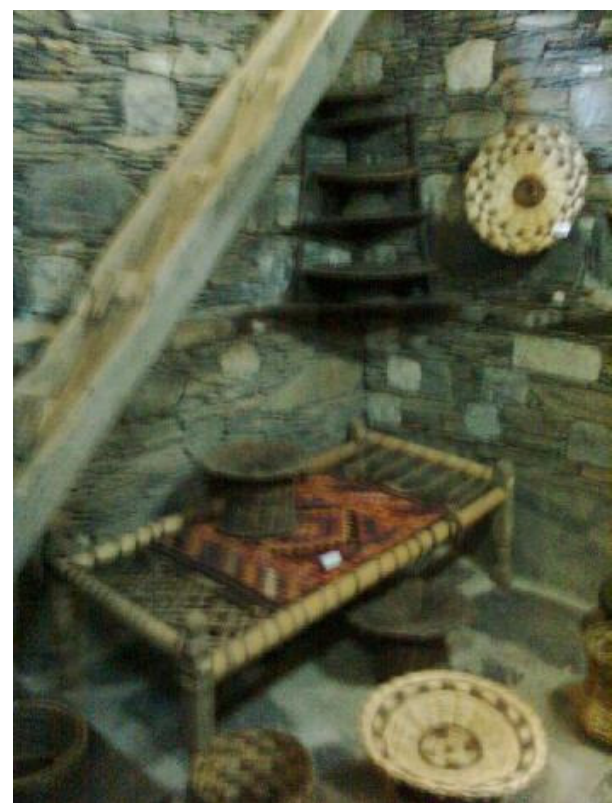

Figure 13. Traditional Kalasha basketry in the museum

Photograph by Author, 2011

\subsection{Effigies of Male Ancestors 'Gandau'}

Kalasha have a unique funerary culture very different from their neighboring Muslim majority. They used to erect wooden effigies of male ancestors on their graves to honor them called gandau in Kalasha language, Klimburg (2008: 171), Kalhoro (2010: 1). Kalasha Museum has some of the specimens in collection that are more recent (see Figure 14) and do not represent the real old ones described and photographed by the early researchers like Morgenstierne (1929), Schomberg (1935) and Klimburg (2008: 189-91). Most of the old pieces are now part of the museum collections across the globe.

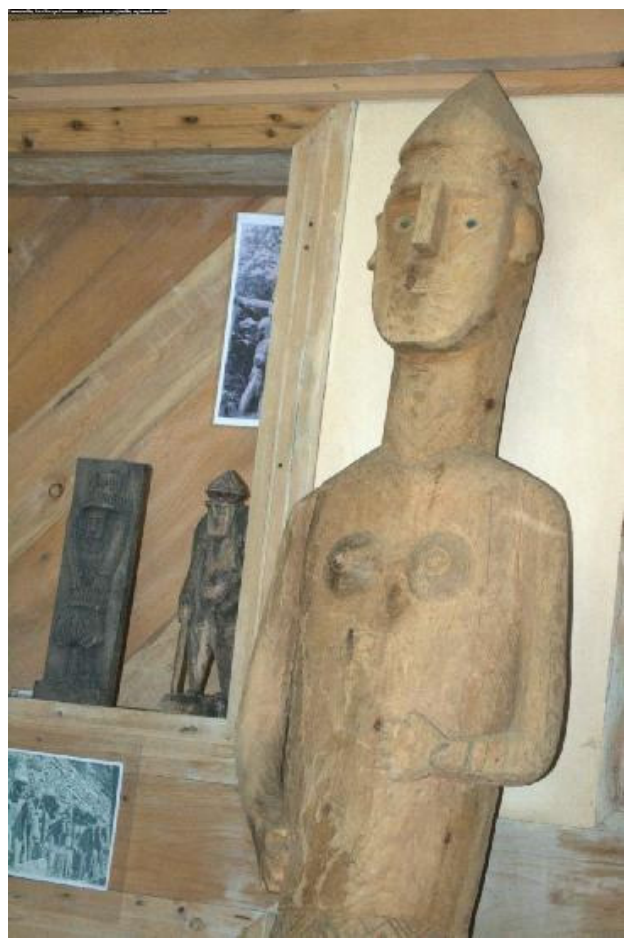

Figure 14. Wooden effigies of male ancestors Gandau in the Kalasha Museum

Photograph by Author, 2011 


\subsection{Household Items}

Museum also house a number of household articles that include stone grinding pieces, wooden buckets and mortar, pestle as well as spoons, saucepans, and other small and big cooking vessels. The utensils are displayed in properly setup rooms in the Museum, (see Figures 15 and 16).

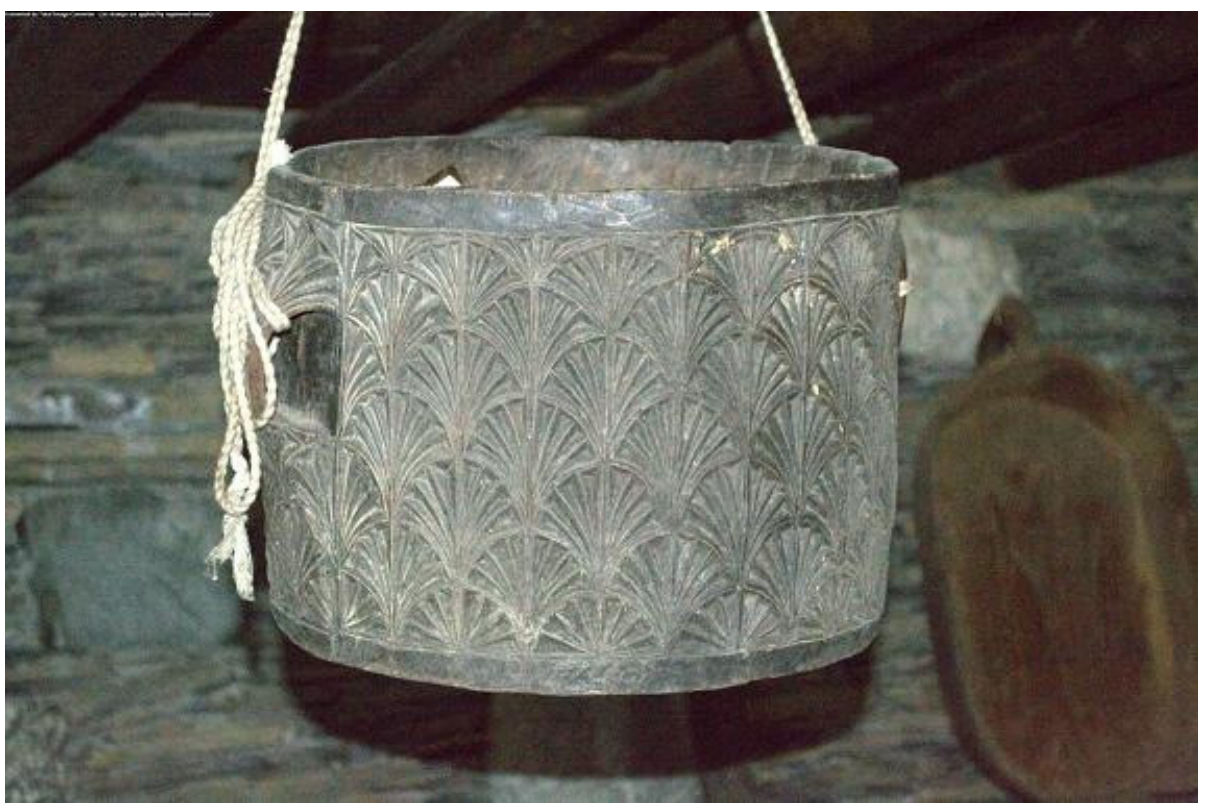

Figure 15. An old wooden carved bucket in museum

Photograph by Author, 2011

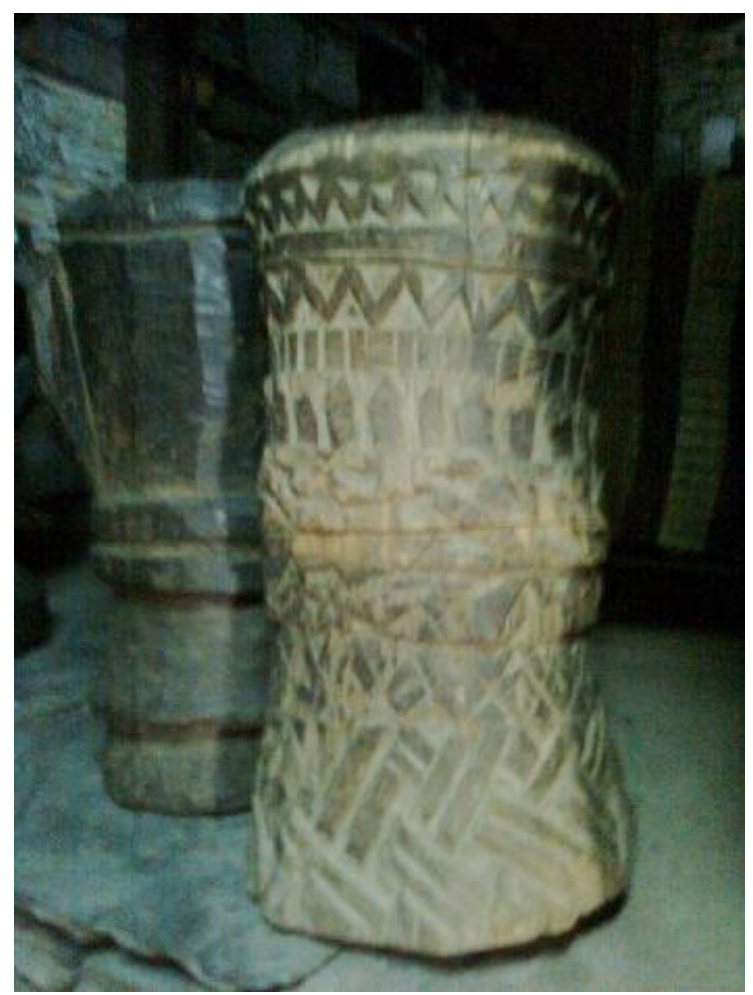

Figure 16. Old wooden household items, like these mortars are part of the museum collections

Photograph by Author, 2011

4.8 Weaving Tools

Kalasha have ancient traditions of spinning and weaving and that is displayed through weaving tools and 
hand-looms displayed in the museum, (see Figure 17). The Kalasha women still actively weave, on similar looms in their free time.

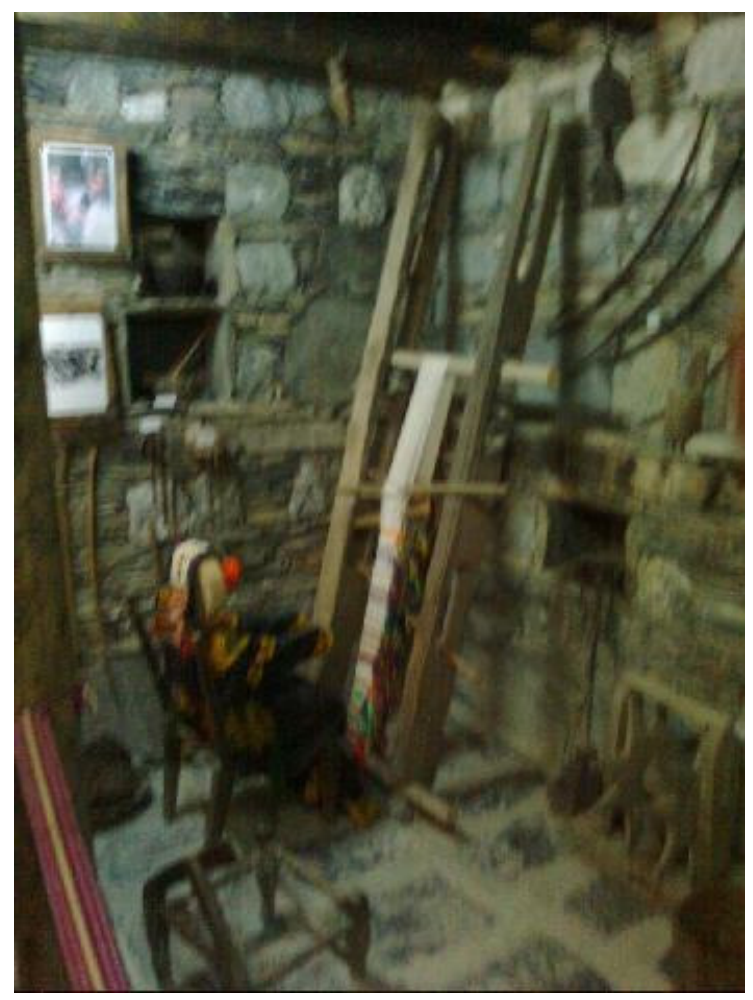

Figure 17. Handloom for weaving colorful belts chehari for women

Photograph by Author, 2011

\subsection{Stone Tools}

The Kalasha Valleys are located in Hindu Kush Mountains, where rocks are in abundance, and so is the use of local stone in making household tools. The Kalsaha Museum has nicely portrayed this part of the Kalsha culture by displaying stone objects and tools within and even outside the Museum, (see Figure 18).

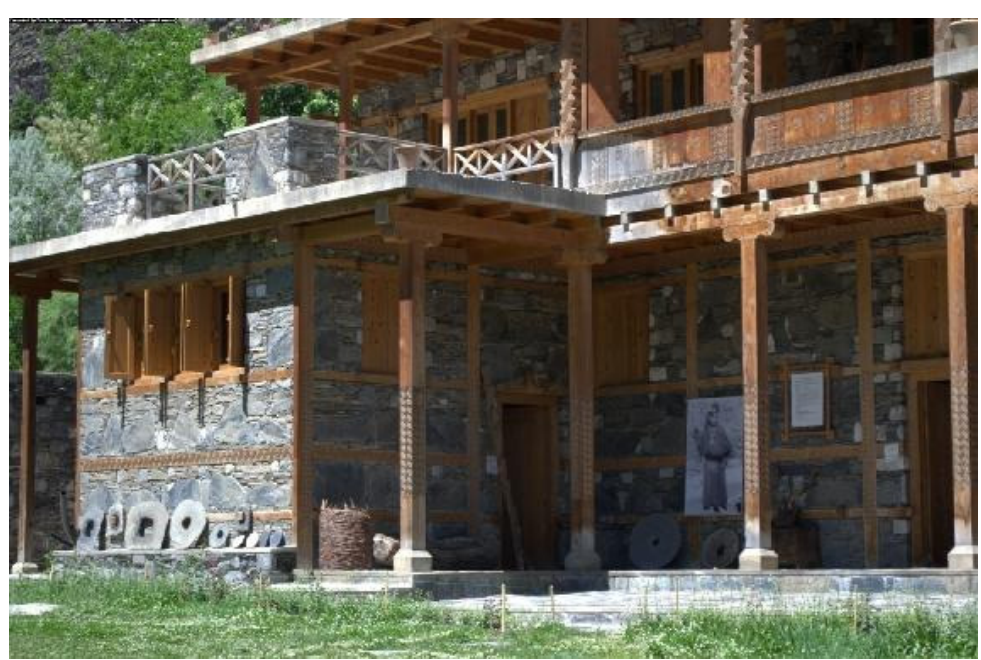

Figure18. Grinding stones displayed outside the Kalasha Museum

Photograph by Author, 2011

\subsection{Carved Wooden Parts of Old Temples}

Wood and wood carvings is very much part and parcel of being Kalasha. Museum has housed carved pieces from old Kalasha Temples depicting the ancient carving patterns, still used in new construction. A good example is the 
door handles used on Kalasha Museum doors, showing a very old traditional style, (see Figure 19).

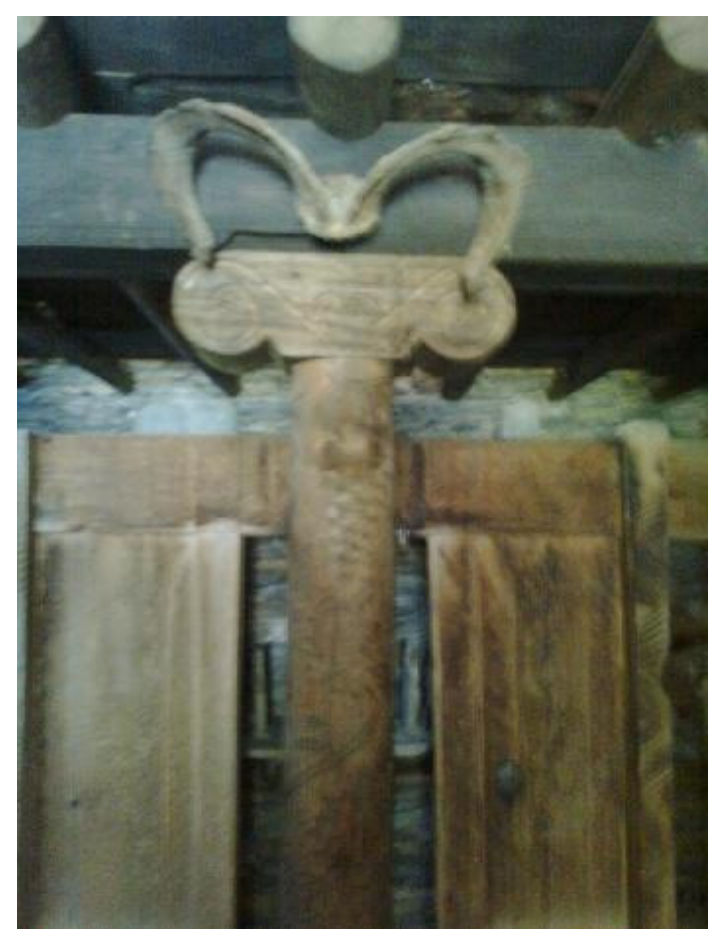

Figure 19. A part of an old wooden temple 'Han'

Photograph by Author, 2011

\section{Ancient Living Style Reproduced}

The museum is setup in a way that has two levels on a corner, where an old traditional room is brought and placed as it used to be hundreds of years ago, for the visitors to have a real feel of Kalasha living quarters and concept of space. The inside of the room gives the exact style of a Kalasha family's one-room living space and what is the interior of a typical bedroom, see Figure 20. The room is furnished in a typical traditional Kalasha sleeping room with traditional furnishings and bedding. Similar one-room Kalasha houses are still common to find in all Kalasha Valleys. This traditional setup reproduced under museum roof is extremely valuable for those interested in studying Kalasha culture and heritage. A thick handmade wooden ladder leads to the room and balcony on the second level of the museum.

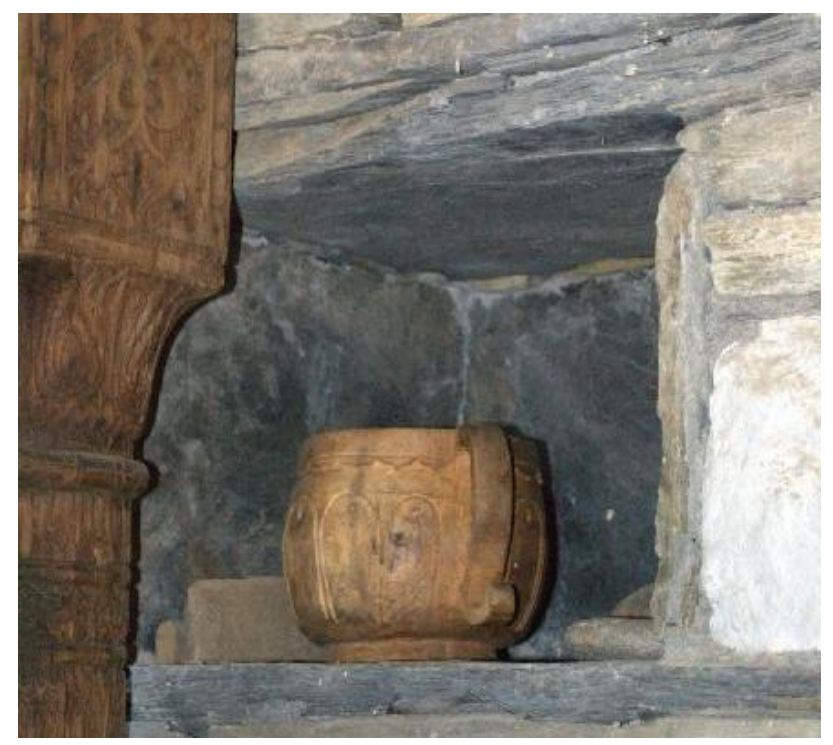

Figure 20. A corner of the old Kalasha home exhibit

Photograph by Author, 2011 


\section{The Museum Shop}

In the back side of the Museum a small Museum Shop is setup by the museum authorities. The shop showcases replicas of various traditional Kalash artifacts. The most popular among these is the Kalasha Doll wearing Kalasha dress (sold for Rs 1500, in summer of 2011). Other items include famous headdress of Kalasha Kupas, wooden utensils, woolen belts, wooden toys, and some jewelry items, (see Figure 21). Kalasha Museum Brochure is also sold to interested visitors both in black and white and in color print for Rupees 10 and 20 respectively. The income of museum from these sales is not much, I was told, as tourists only come during months when Kalasha festivals are held (in May, August, September and December) and weather is clear to travel because of poor road conditions.

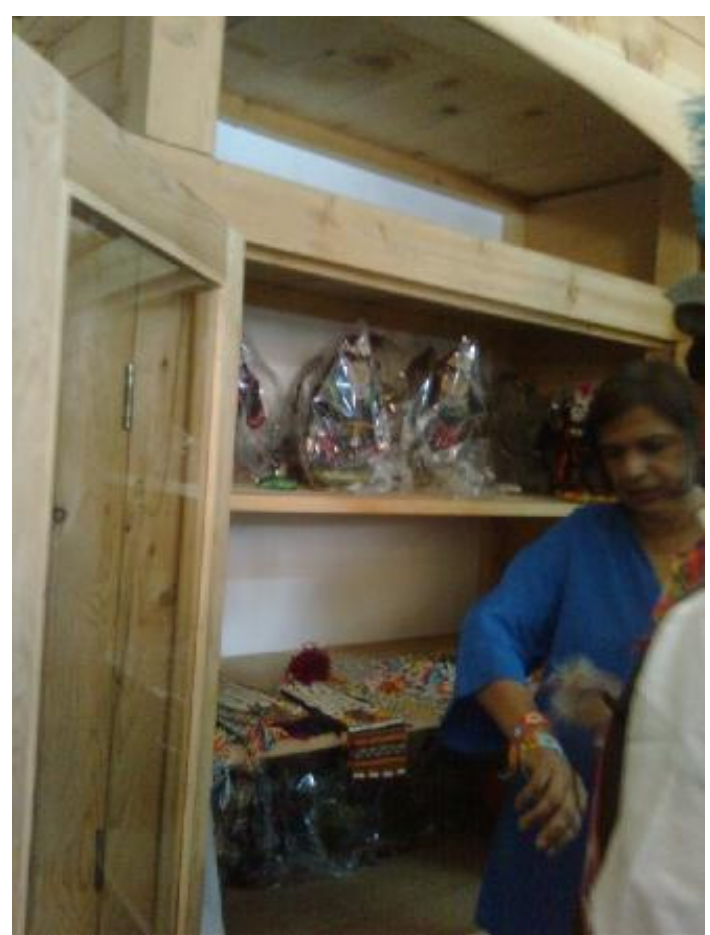

Figure 21. The museum shop showing replicas of Kalasha dolls and Kalasha headdress 'Kupas'

Photograph by Author, 2011

\section{Conclusion}

The establishment of the first Kalasha Museum is a welcome most awaited step taken by the NGO "Greek Volunteers." It is hoped through this article that it will help teach the public about the newly establish Kalasha Museum and the fast disappearing Kalasha people and their ancient culture and also promote awareness and preservation of Kalasha traditions, through further research and documentation, as well as interventions by the international organizations like ICOM, who attend to emergency response [for museums] in case of natural disasters or armed conflict, as is the case in the region where Kalasha Museum is situated.

\section{References}

Abbasi, O. U. R. (2011, June 26-July 3). The Colors of the Kalash. The Express Tribune Magazine.

Activities and Projects by the NGO "Greek Volunteers," In the Kalasha Valleys in N.W.F.P. (now Khyber-Pakhtunkhwa Province) Pakistan. (n.d.): Kefallinias 23, 13561 AGll Anargiri, Athens, Greece.

Buddress, G. (2005). Reflections on the Islamisation of Kafirstan in Oral Traditions. Journal of Asian Civilizations, Masters of Understanding: German Scholars in the Hindu Kush and Karakoram, 1955-2005, XXXI(1-2), 16-35.

Cacopardo, A. M. C. A. S. (2001). Gates of Paristan. Herder Publisher.

CCI Supports International Museum Day. (2012, May 18). What is IMD? Retrieved May 15, 2012, from http://icom.museum/.../what-is-imd.html

Culture Preservation: Experts, scholars for preservation of Kalash Culture. (2012, March, 1). Express Tribune 
Islamabad.

Dani, A. H. (2001). Origin of the Dardic Culture (A new discovery in the Northern Areas of Pakistan) Old Information History of Northern Areas of Pakistan (Upto 2000 AD). Sang-e-Meel Publicatons, Lahore.

Darling, E. G. (1979). Merit Feasting among the Kalasha Kafirs of North Western Pakistan. M. A Unpublished Thesis, University of British Columbia, Vancouver.

FLASH INFO. (2012, April). International Day for Monuments and Sites. Retrieved April 4, 2012, from live.com/mail/PrintMessages.aspx?cpi

Forum UNESCO University and Heritage. (2012). Graveyard Sculptures a Dying Kalash Art. Retreived May 30, 2011, from http://eng.chitraltoday.com/index.php?option=com_content

Frembgen, J. W. (2008). Old Forts in Harban: Settlement and Islamization in Indus Kohistan. Journal of Asian Civilizations, Masters of Understanding: German Scholars in the Hindu Kush and Karakoram, 1955-2005, XXXI(1-2), 253-259.

Graziosi, P. (1961). The wooden statue of Dezalik, a Kalash Divinity, Chitral, Pakistan Man, 148-151.

Graziosi. P. (1964). Italian Expeditions to the Karakorum (K2) and the Hindukush V-Preshistory - Anthropology, Prehistoric Research in Northwestern Punjab, Anthropological Research in Chitral (Vol. 1). Italy.

Israr-Ud-Din, E. B. (Ed.). (1996). Proceedings of the Second International Hindukush Cultural Conference. Oxford University Press, Karachi.

Israr-Ud-Din, E. D. (Ed.). (2008). Proceedings of the third Internatonal Hindukush Cultural Conference. Oxford University Press, Karachi.

Issac, G. (2008). Technology Becomes the Objet: The Use of Eletronic Media at the National Museum of the American Indian. Journal of Material Culture, 13(3), 287-310. http://dx.doi.org/10.1177/1359183508095497

Jettmar, K. (1959). Urgent Tasks of Research among the Dardic Peoples of Eastern Afghanistan and Northern Pakistan. Bulletin of the International committee on Urgent Anthrolological and Ethnological Research, (2), 85.

Jettmar, K. (2008). Petglyphs as Evidence of Religious Configurations? Journal of Asian Civilizations, Masters of Understanding: German Scholars in the Hindu Kuch and Karakoruam, 1955-2005, XXXI(1-2), 65-146.

Jettmar, K. (2008). Status Culture of the Kalasha Kafirs. Journal of Asian Civilizations, Masters of Understanding: German Scholars in the Hindu Kush and Karakoram, 1955-2005, XXXI(1-2), 168-194.

KAL'AS'A DUR. The Kalasha Cultural Centre. (n. d.). Hellenic Aid: Ministry of Foreign Affairs of Greece.

KAL'AS'A DUR (The Kalasha Cultural Centre). (2007). Preserving Aboriginal Heritage: Technical and Traditional Approaches.

Kalhoro, Z. A. (2010). Graveyard sculptures a dying Kalash art. Retrieved May 30, 2011, from http://thekalashatimes.wordpress.com/2010/01/10/313

Klimburg, M. (1999). The Kafirs of the Hindu-Kush: Art and Society of the Waigal and Ashkun Kafirs (Vol. $1 \& 2)$.

Klimburg, M. (2005). Gates of Paristan. History, Religion and Society in the Hindu Kush Reports and Memoirs. East and West, 55(1/4), 502-507.

Klimburg, M. (2008). Status Cultures of the Hindu Kush. Journal of Asian Civilizations, Masters of Understanding: German Scholars in the Hindu Kush and Karakoram, 1955-2005, XXXI(1-2), 168-194.

Lines, M. (1988). Beyond the North-West Fronter (Travels in the Hindu Kush and Karakorams). The Oxford Illustrated Press, England.

Lines, M. (2010). From Disaster to Catastropher. Ushba Publishing International, Karachi.

Loude, J. Y., \& Lievre. (1988). Kalash Solstice. Proceedings of the 3rd International Cultural Conference: Lok Virsa: Islamabad.

Maggi, W. (2001). Our Women are Free (Gender and Ethnicity in the Hindukush). The University of Michigan Press.

Parkes, P. (1983). Alliance and Elopement: Economy, Social Order and Sexual Antagonism among the Kalash 
(Kalash Kafirs) of Chitral. D. Phil Thesis, University of Oxford.

Preserving Aboriginal Heritage: Technical and Traditional Approaches, Ottawa. (2007). Retrieved January 19, 2012, from http://www.cci-icc.gc.ca/symposium/2007/index-eng.aspx

Rana, S. (2011, April 19). The Kalasha Struggle to Preserve their Culture. The Express Tribune.

Shubinak. (2012). Retrieved April 21, 2012, from http://www.shubinak.com/website/Welcome-to-Shubinak

Snoy, P. (2008). The Rites of the Winter Solistice among the Kalash Bumburet. Journal of Asian Civilizations, Masters of Understanding: German Scholars in the Hindu Kush and Karakoram, 1955-2005, XXXI(1-2), 36-64.

Sperber, B. G. (1996). Kalash: Dress and Textile Techniques. Paper presented at the Proceedings of the Second International Hindukush Cultural Conference.

Trail, R. L., \& Cooper, G. R. (1999). Kalasha Dictionary _ with English and Urdu. Studies in Languages of Northern Pakistan, Volume 7. National Institute of Pakistan Studies, Quaid-e-Azam University, [Islamabad] Pakistan and Summer Institute of Linguistics, UK.

Wutt, K. (1978). The Architecture of Some Valleys in the Hindukush. Doctoral dissertation Institute of Ethnology, Vienna University. 